\title{
Professor Titular Amauri Mascaro Nascimento
}

\author{
A Redação
}

\begin{abstract}
Em 15 de maio de 1979, teve lugar no Salão Nobre da Faculdade de Direito a solenidade de posse do novo Titular de Direito do Trabalho, Prof. Amauri Mascaro Nascimento. A Professora Nair Lemos Gonçalves, no discurso de saudação, destacou a importância da obra do mestre, cujas pesquisas, amplas e atuais, abrangem o Brasil e os principais países, e "constituem subsídio seguro, não só para estudo dos alunos e especialistas, como também para os 6́rgãos governamentais encarregados dos problemas do trabalho".

No discurso de agradecimento, o novo titular salienta dois aspectos importantes no campo do Direito do Trabalho no Brasil: a relevância que deve ser dada aos bens do trabalho, fruto do espírito do homem e fator de liberdade para a humanidade, e o aspecto social que envolve a organização dos sindicatos, que devem ser livres e responsáveis. Homenageia ainda o Prof. Emérito Cesarino Júnior, por sua capacidade e pioneirismo no Direito Social e termina com uma oração à Academia, fonte de inspiração a poetas e juristas, que sempre ergueram bem alto a bandeira da liberdade e cujos mestres sempre mostraram ao pais os caminhos do Direito e da Justiça Social.
\end{abstract}

\section{O Novo Titular}

O novo titular de Direito do Trabalho, Professor Dr. Amauri Mascaro Nascimento, nasceu em Campinas, Estado de São Paulo, aos 4 de setembro de 1932, filho do Professor Alcides do Nascimento e da Professora Alice Mascaro Nascimento.

Fez os cursos ginasial e científico no Colégio Cesário Motta, em Campinas, concluindo o último no Instituto Caetano de Campos, em São Paulo.

Bacharelou-se em Direito pela Faculdade de Direito da Pontifícia Universidade Católica de São Paulo, tendo sido orador da sua turma, de 1957.

Foi secretário geral da União Nacional dos Estudantes.

Ingressou no curso de Pós-Graduação da Faculdade de Direito da Universidade de São Paulo, especializando-se em Teoria Geral do Estado e Filosofia do Direito.

Prestou concurso para Promotor de Justiça do Estado de São Paulo em 1958, classificou-se em 2.0 lugar e assumiu diversas Promotorias de Comarcas do interior do Estado de São Paulo. 
Em 1961, por concurso, ingressou na Justiça do Trabalho Segunda Região, como Juiz do Trabalho substituto. Foi promovido, por merecimento, em 1967, para Juiz Titular Presidente de Junta de Conciliação e Julgamento. Desde 1961 é Juiz Diretor do Fórum e a partir de 1978 recebeu convocações para substituição no Tribunal Regional do Trabalho.

Começou a carreira docente em 1964 lecionando Instituições de Direito Público e Privado na Faculdade de Economia, Administração de Empresas e Ciências Contábeis da PUC de São Paulo, da qual se tornou Professor Contratado de Legislação Social e, a partir de 1974, de Direito do Trabalho na Faculdade de Direito. Em 1968 foi contratado Professor Titular de Direito do Trabalho das Faculdades Metropolitanas Unidas de São Paulo.

Na Universidade de São Paulo iniciou carreira em 1974, como Professor Assistente-Doutor lecionando Filosofia do Direito. No mesmo ano defendeu tese de livre-docência perante banca constituída pelos professores Dr. José Pinto Antunes, Dr. José Cretella Júnior, Dr. José Martins Catharino, Dr. Messias Pereira Donato e Dr. Osiris Rocha, obtendo aprovação e se tornando Professor do Departamento de Direito do Trabalho.

Em 1978 obteve o grau de Professor-Adjunto de Direito do Trabalho. Em novembro desse mesmo ano, prestou concurso para Professor Titular de Direito do Trabalho, defendendo a tese "Conflitos Coletivos de Trabalho" perante banca examinadora integrada pelos professores Doutores Cretella Júnior, Geraldo de Camargo Vidigal, José Martins Catharino, Geraldo Bezerra de Menezes e Orlando Gomes, merecendo classificação em primeiro lugar.

O Professor Amauri fez várias conferências em cursos de aperfeiçoamento, de especialização e seminários, sobre temas de sua especialidade, como "Transferência de Empregados", "Temas Fundamentais de Filosofia do Trabalho", "A Nova Lógica de Interpretação do Contrato de Trabalho", todas realizadas na Universidade de São Paulo.

Foi conferencista no "Simpósio sobre Juízes Classistas" da Justiça do Trabalho, a convite das Federações de Empregados e Empregadores, realizada no Palácio do Itamaraty.

$\mathrm{Na}$ Associação dos Advogados de São Paulo, em ciclo de Palestras, proferiu: "Execuções Trabalhistas", "Principais Repercussões do Novo Código Civil no Processo Trabalhista"; na Pontifícia Universidade Católica de São Paulo, discursou sobre: 


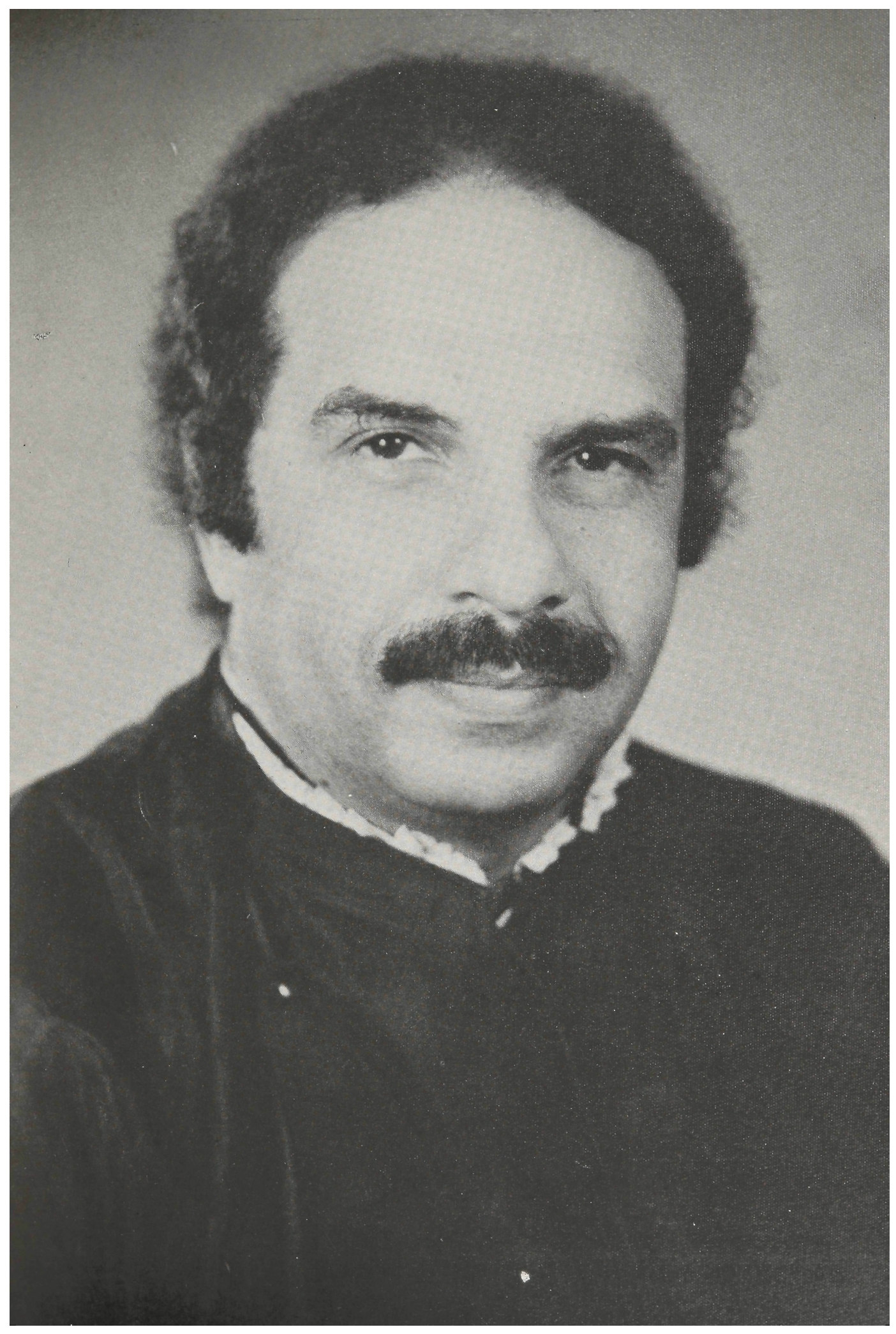


Professor Titular de Direito do Trabalho,

Dr. Amauri Mascaro Nascimento. 
"Medida Liminar nas Reclamações Trabalhistas sobre Transferência de Empregados", "Contrato de Trabalho", "Estabilidade e Fundo de Garantia por Tempo de Serviço", entre outros.

O Novo Titular é membro de Associações, Nacionais e Internacionais, ligadas à área de Direito e Letras. Pertence à Associação dos Magistrados da Justiça do Trabalho, da qual foi presidente em 1977; é Acadêmico da Academia Paulista de Direito, da Academia Paulista de Letras Jurídicas e da Academia Nacional de Direito do Trabalho.

No Estado de São Paulo, pertence ao Instituto dos Advogados e ao Instituto de Direito Social; é membro da União Brasileira de Escritores, do Centro Interamericano de Direito Processual do Trabalho e do Instituto Latinoamericano de Derecho del Trabajo y de la Seguridad Social. É conselheiro da Associação dos Magistrados Brasileiros.

\section{Bibliografia}

O Professor Amauri Mascaro Nascimento escreveu diversas obras importantes no campo do Direito do Trabalho. É autor dos seguintes livros:

- O Salário no Direito do Trabalho. São Paulo, LTr, 1968.

- Fundamentos do Direito do Trabalho. São Paulo, LTr, 1970.

- Instituições de Direito Público e Privado. São Paulo, Atlas, 1972 (em co-autoria).

- Contrato de Trabalho. São Paulo, LTr, 1971.

- Iniciação ao Direito do Trabalho. São Paulo, LTr, 1975.

- Compêndio de Direito do Trabalho. São Paulo, LT, 1976.

- Curso de Direito Processual do Trabalho. São Paulo, Saraiva, 1978.

\section{A Posse}

A 15 de maio de 1979, reuniu-se a Congregação de Professores no Salão Nobre desta Faculdade, para receber solenemente o novo Titular de Direito do Trabalho, Professor Amauri Mascaro Nascimento.

O homenageado foi introduzido no doutoral pelos Professores Goffredo da Silva Telles, João Baptista de Oliveira e Costa Júnior, e Rui Barbosa Nogueira; e foi convidada para saudá-lo a Professora Nair Lemos Gonçalves, que ressaltou as quali- 
dades do Novo Titular, como magistrado, mestre e autor de importante bibliografia especializada.

Em brilhante exposição, o Professor Amauri agradeceu a saudação e teceu considerações sobre o papel social da disciplina que leciona, e os aspectos filosóficos que emanam da ideologia do Direito Social.

Publica-se a seguir o Discurso de Saudação ao Novo Titular, proferido pela Dra. Nair Lemos Gonçalves, e o discurso de Agradecimento do Professor Amauri Mascaro Nascimento.

\section{Discurso de Saudação de Nair Lemos Gonçalves}

\footnotetext{
"Der Mensch vermag gar manches durch zweckmässigen Eigenschaften gleichmässig in ihm vereinigen."

Gebrauch einzelner Kräfte, er vermag Ausserordentliche durch Verbindung mehererer Fähigkeiten; aber das Einzige, gans Unerwartete leistet er nur, wenn sich die sämtlichen GoETHE
}

É justo nosso orgulho de saudar o novo Titular de Direito do Trabalho, AmaURi MASCARo NASCimento, o colega, o professor, o magistrado, o jurista por todos admirado.

Dele muito pode esperar o Direito do Trabalho porque, nascido em Campinas em 4 de setembro de 1932, tem pela frente uma vida inteira de profícua atividade, que se pode avaliar por seu passado brilhante.

A partir de 1968 produziu praticamente um livro por ano, abrangendo a maioria dos temas de Direito do Trabalho e da Segurança Social, além de numerosos artigos em revistas especializadas e conferências em quase todos os Estados brasileiros.

Não parou aí, pois esteve sempre ativo na magistratura do trabalho onde, pelos seus méritos galgou, por eleição, a Presidência da Associação dos Magistrados da Justiça de São Paulo da $2 .^{a}$ Região e foi, repetidas vezes, convocado para o Tribunal Regional da mesma Região.

Marcante sua atuação no magistério, onde vem granjeando um amigo em cada aluno desta Faculdade e das outras instituições universitárias a que pertence: Pontifícia Universidade Católica e Faculdades Metropolitanas Unidas.

Foi ainda membro fundador da Academia Paulista de Direito, na qual ocupa, na qualidade de Acadêmico Titular, a Cadeira n. ${ }^{\circ} 30$, tendo por patrono o grande Evaristo DE MORAES ; 
da Academia Brasileira de Direito do Trabalho e do Instituto de Direito do Trabalho de São Paulo, que ajudou a organizar e cujos cursos vem prestigiando. É membro também do Instituto dos Advogados de São Paulo, do Instituto de Direito Social, do "Instituto Latinoamericano del Derecho del Trabajo y de la Seguridad Social" e da "Associacion Iberoamericana de Derecho del Trabajo".

Qualidade rara nota-se na obra do Professor AMAURI: Suas pesquisas, que são amplas, abrangendo os principais países e atualizadas não só quanto ao Brasil, visam sempre ao aperfeiçoamento das instituições para que atendam à realidade brasileira e constituem, por isso, subsídio seguro não só para estudo dos alunos e especialistas, mas também para os órgãos governamentais encarregados dos problemas do trabalho.

Profundamente interessado em filosofia, especialmente a do direito, entrou em 1972 para o corpo docente desta Faculdade como Professor Assistente Doutor do Departamento de Filosofia e Teoria Geral do Direito. Só depois, em 1974, convidado pelo eminente Professor Emérito ANTONIo FERREIRA CESARINo JúNIOR, então Chefe do Departamento de Direito do Trabalho, transferiu-se para este último Departamento e, conseqüentemente, para o campo de especialização que escolhera como magistrado e no qual elaborara a maioria de seus trabalhos científicos. Na área do Trabalho tornou-se Professor Livre Docente, Professor Adjunto e alcançou o mais alto galardão da carreira universitária.

Vem lecionando nesta Faculdade em todos os níveis: ciclos institucional e de especialização, curso de pós-graduação onde, a partir de 1975, ministrou disciplinas de direito comparado, focalizando o contrato individual de trabalho, o processo trabalhista e o direito protecionista do trabalho, com pleno êxito e classes numerosas.

Sua colaboração foi preciosa na organização dos cursos interdisciplinares de extensão universitária em direito do trabalho e previdência social, realizados pelo Departamento de Direito do Trabalho, cujo Conselho muito vem lucrando com a sua eficiente participação.

Nada teve de fácil sua rápida carreira, pois deve todas as posições a sérios e árduos concursos de provas e títulos.

Dedicado ao ramo do direito que se preocupa em equilibrar as forças do capital e do trabalho, o econômico e o social, ou melhor, a justiça social e o desenvolvimento econômico, sem esquecer a garantia de direitos individuais impostergáveis, 
possui o Professor AmaURI as qualidades pessoais indispensáveis ao especialista: humildade, própria dos verdadeiros sábios, espírito humanitário, perseverança e continuidade nos estudos para o necessário aprimoramento da cultura, força de trabalho dos maduros jovens que sabem o que desejam da vida, sem lhe faltar a capacidade para o trabalho em equipe, único realmente compatível com as tarefas universitárias e reconhecido pela Conferência Geral da UNESCO, quando inclui, como qualidade imprescindível ao pesquisador científico, entre outras, a

“disposição para comunicar-se com outros nảo só em círculos científicos e tecnológicos como também fora desses círculos, que implique disposição para trabalhar em equipe e em contexto multiocupacional" (Recomendação sobre status de Pesquisadores Científicos, aprovada em 20-11-74, em Paris. Trad. de Leonidas Gontijo de Carvalho in Ciência e Cultura vol. 30 (12, dezembro de 1978, p. 1.441).

Aos pais, Alice Mascaro Nascimento e Allcides NasciMENTO, já falecidos, teve a felicidade de proporcionar em vida muitas alegrias e orgulho quando se revelou estudante dedicado, eficiente e inteligente e obteve as primeiras vitórias nos concursos de Promotor Público, Juiz do Trabalho, doutoramento em filosofia, livre docência e Professor Adjunto de Direito do Trabalho.

Exemplar esposo e pai, encontra na Sra. NEUZA CosTa NASCIMENTO a companheira perfeita e incentivadora, que sabe compreender as renúncias a que está obrigado o profissional intelectual, até mesmo aos momentos de repouso, recreação e contato familiar tão importantes. $\mathrm{E}$ nos filhos SôNIA APARECIDA e MARCELo tem mais um poderoso motivo para lutar e progredir.

Deixemos que a obra fale pelo seu autor, a fim de tornar menos incompleto o retrato do Professor AMAURI MASCARo NASCIMENTO, que tentamos traçar no exíguo espaço próprio desta solenidade, onde todos aguardam com ansiedade a palavra do novo Mestre.

"O Direito do Trabalho surge como a mais autêntica expressão de humanismo jurídico e como a grande arma de renovação social, pela sua total identificação com as necessidades e aspirações concretas do grupo social diante dos problemas decorrentes da denominada questão social". . "é a mais legítima manifestação da ordem jurídica voltada para o homem como 
a medida de todas as coisas..." (Iniciação ao Direito do Trabalho, 3. ${ }^{\mathrm{a}}$ ed., S. Paulo LTr., 1978, p. 24).

"O Juiz do Trabalho é a figura do equilíbrio no relacionamento entre a grande massa trabalhadora e a elite empresarial... Valoriza o homem, nivelando na mesa de audiência o hipossuficiente e o economicamente forte... Promove o diálogo que jamais foi entabolado ou reata o diálogo que veio a ser interrompido..." (Curso de direito processual do trabalho. S. Paulo. Saraiva, 1978, p. 11)

$O$ contrato de trabalho significa

"um ideal de humanismo na preservação da dignidade do homem que trabalha e uma forma de liberdade pessoal consubstanciada na livre escolha de emprego" (Compêndio de direito do trabalho, 2. ${ }^{a}$ ed. S. Paulo, LTr/Ed. Univ. S. Paulo, 1976, p. 279)

Depois de esclarecer o predomínio do entendimento de que o salário deve ser pago, ainda que nulo o contrato de trabalho, com fundamento ou na irretroatividade da declaração da nulidade, ou no princípio que veda o enriquecimento ilícito, afirma o Professor Amauri que, de outro modo

"Seria .. premiar o infrator, dispensando-lhe um tratamento privilegiado perante os demais empregadores que são obrigados a suportar os ônus decorrentes da relação de emprego. Além desse aspecto de eqüidade de tratamento, é preciso entender que o empregado que desenvolve uma atividade ilícita nem sempre o faz com o fim de descumprir a lei, mas com o propósito de encontrar meios de subsistência. Importaria numa dupla punição, a penal a que se sujeita se efetivamente comete a infração criminal e a trabalhista, não prevista em lei, privá-lo do salário". (O salário no direito do trabalho. S. Paulo, LTr., 1975, p. 112)

Sobre as formas de solução dos conflitos do trabalho entende o novo Mestre que

“... o direito do trabalho precisa de técnicas ágeis, de fácil aplicação, institucionalizadas, para acompanhar na mesma velocidade o ritmo das modificaçc̃es, fim para o qual só a lei não é suficiente, porque seu processo de elaboração é demorado e inadequada, porque seria inviável leis para resolver cada conflito coletivo". (Conflitos Coletivos de Trabalho: funda- 


\section{8}

mentos do sistema jurisdicional brasileiro. S. Paulo, Saraiva, 1978, p. 79)

Da rápida visão que procuramos dar da maneira como o Professor AMAURI MASCARO NASCIMENTo utiliza, em sua brilhante carreira, as qualidades que lhe são próprias, é fácil concluir haver ele atingido aquele ideal goethiano que lembramos no início desta saudação.

Ao novo titular, todas as felicidades.

\section{Discurso de Posse de Amauri Mascaro Nascimento}

Desculpem-me, mas não me estenderei. Não que dê ao ato relevância menor do que a que tem. Ao contrário. Não encontro meios de traduzir toda sua magnitude. Assim, limito-me ao essencial. Creio na valorização do trabalho. Dou-lhe a primazia no Estado do bem-estar social.

Perde-se no tempo a época na qual o dualismo entre contemplação e ação separou em uma antinomia injustificável o homo sapiens do homo faber.

Felice Battaglia, na sua monumental Filosofia del Lavoro, oferece-nos lições nunca demais repetidas:

"Enquanto o trabalho foi considerado atividade inferior em relação ao pensamento, enquanto os bens do trabalho apareceram como inferiores em relação aos da mente, havendo, de um lado, homens contemplativos e, de outro, homens condenados a ocupar-se na matéria, não houve certamente possibilidade de tomar-se o trabalho como apresentando significação educativa."

Hoje, o homem intelectual é homem do trabalho, a atividade manual é manifestação da personalidade e a sociedade empresarial só se completa e dinamiza como sociedade de trabalho.

Sei bem que a idéia de uma sociedade de trabalho, pressupondo a igualdade, acabaria levando-nos à ameaça da liberdade.

Ninguém deseja como princípio fundamental de convivência humana, a supressão da liberdade.

Mas é preciso reconhecer que as vias do liberalismo mal praticado nos levaram à questão social que desde a Revolução 
Industrial do Séc. XVIII desafia a nossa capacidade de encontrar soluções eficazes contra os seus indesejáveis efeitos.

Por outro lado, as instaurações coletivas conduziram alguns povos à perda do direito de iniciativa da qual resulta o sacrifício da individualidade e a formação de grupos humanos inertes e massificados sem espaços maiores para a liberdade de cada um.

É preciso continuar a árdua tarefa da escolha do terceiro caminho, síntese dos dois anteriores, e construir uma organização política e social mais justa na qual as liberdades formais transformem-se em liberdades reais e os resultados da produção econômica, do progresso técnico e do desenvolvimento científico possam ser desfrutados por todos.

A começar pela compreensão do trabalho.

$O$ trabalho não é mercadoria. $O$ trabalhador não é objeto lançado em um mercado de trabalho. O salário não é preço do trabalho, passível das oscilações da lei da oferta e da procura.

O mercantilismo dessas concepções, depois das idéias sobre o sentido do trabalho, do Renascimento e do Idealismo, não pode ser aceito.

É responsável pela política legislativa que pode levar o Direito do Trabalho à negação dos seus próprios fins.

0 trabalho é desdobramento do espírito enquanto atividade, parte integrante do homem, da sua personalidade, do seu próprio ser.

Com o trabalho e onde está o trabalho, estará presente o ser humano que o presta e que dele é indissociável.

$O$ contrato de trabalho, pelo seu significado, não é apenas a forma jurídica do vínculo entre empregado e empregador. Tem natureza mais expressiva porque além do conteúdo jurídico tem um conteúdo ético também, que deve levar as suas partes a um relacionamento fundado em propósitos de harmonização dos interesses contrapostos.

Para que o homem não entorpeça na fábrica ele deve merecer cuidados voltados para o seu bem-estar físico e moral. A relação entre o homem e o fator técnico exige uma legislação tutelar da saúde, da integridade física e da vida do trabalhador em condições de cumprir as suas finalidades. Não é possível, como diz Cabanellas, o sacrifício de vidas humanas pela simples necessidade de aumentar ou melhorar a produção.

São louváveis, portanto, as atenções dispensadas pela Organização Internacional do Trabalho para induzir os Gover- 
nos a fixar certos objetivos concretos, a traçar normas destinadas à redução excessiva do trabalho, à adaptação dos horários de serviço em moldes de maior flexibilidade, permitindo trabalho, formação e tempo livre, principalmente nos grandes centros urbanos que consomem horas de trajeto entre a moradia e o local da atividade.

Noto uma reação contra a desumanização da vida.

Expressa-se no inconformismo dos grupos profissionais que, premidos pelas condições insustentáveis em que se acham, reagem contra as leis e protestam pelas suas modificações.

Tenho a esperança de que conseguiremos encontrar, nas transformações das nossas leis trabalhistas confiadas ao debate da Nação, as soluções que atendam às aspirações da sociedade civil.

Dentre elas, ponho em destaque a importância da garantia do emprego contra dispensas imotivadas e acompanho os juristas que têm mostrado as vantagens que poderá trazer.

Inexistindo razões de ordem econômica, financeira, técnica ou disciplinar, nada justifica despedir o empregado, privando-o da fonte da qual recebe os meios para a sua subsistência pessoal e familiar. Outros sistemas jurídicos, como o da República Federal da Alemanha, puseram em prática o direito ao emprego e vedam a rescisão do contrato de trabalho por ato unilateral e imotivado do empregador. Razões existem para que em nosso País medidas análogas sejam adotadas. O Fundo de Garantia do Tempo de Serviço, apesar dos benefícios econômicos que trouxe, contribuiu para a instabilidade do emprego e a rotatividade do trabalhador entre as empresas do mesmo setor, em prejuízo do seu nível salarial que em decorrência dessa prática não se eleva na mesma medida do aumento do custo de vida.

Há, de outro lado, como efeito da mesma causa, o constrangimento do empregado em exercer o direito de ação para reclamar perante a Justiça do Trabalho as reparações cabíveis sem pôr em risco o emprego; desse modo, a nulidade da despedida imotivada é indispensável e inadiável conquista jurídica e social, condição mesma da manutenção dos direitos trabalhistas durante o desenvolvimento do vínculo empregatício e que não pode ficar fora do quadro das medidas com as quais procuramos aperfeiçoar o nosso sistema legal.

Toda análise que se faça das relações coletivas de trabalho deve considerar que sempre há uma latente reivindicação do grupo profissional. Seria ilusório supor que os trabalhadores estão satisfeitos e nada mais pretendem do Estado e dos empre- 
gadores. Assim, os conflitos trabalhistas são uma constante na vida dos grupos sociais; precisamos aprender a conviver com eles e institucionalizar mecanismos permanentes de solução que permitam o diálogo antes da decisão judicial. Temos sempre que renovar as condições de trabalho para que, sendo mais favoráveis ao trabalhador, sem prejuízos do equilíbrio da economia, mantenha-se a estabilidade social.

Quando falham todas as tentativas de negociação coletiva, é à jurisdição que deve ser atribuída a função de decidir as controvérsias e é o processo judicial o instrumento da nossa civilização para a composição dos conflitos de interesses.

Porém, a jurisdição só poderá desempenhar bem as suas funções nos dissídios coletivos desde que disponha dos instrumentos legais para que possa agir com maior amplitude diante das pretensões contrapostas. Merece atenta análise da Nação o novo critério proposto, de aumentos salariais em índices que reflitam o crescimento da produtividade e os lucros do empregador, verificados através de critérios técnicos e periciais. Seria uma experiência nova de participação do empregado nos lucros e no desenvolvimento econômico, instituída pela via judicial.

Antes, porém, da transferência do conflito para a esfera do Estado, quer para a mediação da Delegacia Regional do Trabalho, quer para a jurisdição da Justiça do Trabalho, a autocomposição das partes deve ser incentivada pelas leis, criando-se na própria empresa um canal permanente de negociação. Nesse ponto, o arquivado anteprojeto do Código do Trabalho, de autoria do ilustre jurista Evaristo de Moraes Filho, apresentou soluções que, devidamente reavaliadas, podem dar às empresas uma função social e não apenas econômica, nos moldes exercitados em outros países, preconizados pela nossa constituição federal e em consonância com as medidas que são anunciadas, permitindo a sua melhor execução.

O Direito Sindical brasileiro padece do mal, superável, da contradição.

Nasceu embalado no colo do Estado, acalentado pela cantiga da Carta Constitucional de 1937, em cujos braços envolventes viveu a adolescência de um período intervencionista, do qual só agora procura libertar-se, sem que os elos que o prendem ao Estado, transpostos para a CLT, tenham sido quebrados.

$O$ sindicato, para constituir-se, depende de carta de reconhecimento expedida pelo Ministério do Trabalho. 0 reconhecimento pode ser negado. Se concedido, o Estado tem o poder de retirá-lo, como também, pode interferir na administração 
do sindicato. Os estatutos sindicais são padronizados. Confere-se ao sindicato o direito de cobrar contribuições, mesmo de não associados, desde que pertencentes à categoria.

Esse sindicalismo é de direito público.

Se pretendemos um sindicalismo de direito privado, as leis precisam ser reformuladas, não se afastando das diretrizes gerais traçadas pela Convenção n. 87 da Organização Internacional do Trabalho.

A contradição permanecerá enquanto ficarmos com um pé no passado e outro no futuro, entre as leis sindicais vigentes e as idéias de renovação segundo o princípio da liberdade sindical.

Precisamos, antes de mais nada, definir a filosofia sindical que pretendemos seguir. De nada adianta querer um sindicalismo democrático e praticar um sindicalismo corporativista.

Penso que a autonomia sindical absoluta não é fácil numa sociedade que não tem o costume de praticá-la. Em teoria implica, como nos ensina Giuliano Mazzoni, na autonomia de organização, na autonomia de administração e no exercício da autotutela. Da primeira resultaria o pluralismo sindical, e o pensamento predominando no Brasil segue o princípio do sindicato único. Da segunda seguir-se-ia a proibição ao Estado de intervir no sindicato, e entre nós já seria um passo significativo submeter essa intervenção ao controle judicial. Da terceira resultaria a exacerbação da greve e o alheiamento do Estado das disputas sociais entregando-se os grupos às pressões recíprocas, e a greve no nosso meio tem sido um recurso extremo do qual os trabalhadores lançam mão só quando estão premidos pelas dificuldades, para a satisfação das suas necessidades vitais mínimas.

Portanto, a idéia de sindicalismo que podemos ter não deve situar-se nos extremos das linhas do pensamento. Não seguimos o sindicalismo revolucionário e não devemos manter o sindicalismo de participação no qual o sindicato exerce funções delegadas do Estado e este obsorve os líderes sindicais.

Precisamos de um sindicalismo livre, mas não irresponsável, e que saiba dosar a dimensão dos seus passos.

Necessitamos de um sindicalismo patronal que na pauta das negociações coletivas recuse-se a tudo, menos a um dever fundamental, único capaz de conquistar a indispensável confiança dos trabalhadores: a sinceridade nas informações sobre a capacidade da empresa em absorver aumentos salariais, para 
que as convenções coletivas transformem-se num meio normal o rotineiro de entendimento.

Esses são os aspectos que julguei oportuno ressaltar nesta ocasião. mim.

Quero dizer, também, o significado desta Faculdade para

Dela sempre recebi incontáveis estímulos.

Fui aluno de alguns dos seus eminentes professores catedráticos e titulares de modo que não é de hoje que a todos respeito e admiro.

Esta não só é a Academia dos grandes momentos históricos nacionais desde os seus primórdios até os nossos dias; não só é a fonte na qual os maiores poetas encontraram inspiração, os maiores juristas defenderam a liberdade, os mais notáveís estadistas empolgaram a Nação, os mais aureolados romancistas receberam as suas primeiras motivações.

É, também, a Academia de Castro Alves, do período romântico e da poesia social, sonorizando os gritos pela abolição da escravatura nos versos de "Vozes d'Africa", "O Navio Negreiro", "A Canção do Africano" e tantas outras poesias; a Academia das idéias trabalhistas que Júlio de Castilho levou para o Rio Grande do Sul em 1891, antecipando-se às primeiras constituições das Américas; a Academia dos pronunciamentos de homens com a autoridade de Rui Barbosa e que proclamaria no Rio de Janeiro na conferência do Teatro Lírico a necessidade de leis de proteção ao trabalhador; a Academia dos estudantes que sempre se levantaram quando o ideal exigiu; a Academia dos eminentes mestres que sempre mostraram ao País os caminhos do Direito e da Justiça Social. Júnior.

Presto minha homenagem ao Emérito Professor Cesarino

Seu nome está inscrito na história do Direito do Trabalho.

Colhemos, hoje, a safra nos campos em que semeou desde 1938, com incansável e lúcida atividade que o levou a construir onde antes nada havia.

Com muito carinho agradeço as palavras com que a Professora Nair Lemos Gonçalves recebeu-me em nome da Congregação.

Sou obrigado a concordar quando diz que o homem pode realizar muito quando se empenha com todas as forças de que é dotado. 
Devo, no entanto, acrescentar que, quanto a mim, só os esforços de nada valeriam.

Sem que o acaso me favorecesse, não estaria aqui.

Combinam-se, na trama da vida, o determinismo e o acaso.

Talvez sejam acertadas as afirmações que Raul de Leoni faz em forma de poesia:

"O homem desperta e sai cada alvorada

Para o acaso de cousas... e, à saída,

Leva uma crença vaga, indefinida

de achar o Ideal nalguma encruzilhada..."

Comemora-se hoje o octogésimo oitavo aniversário da publicação da Encíclica "Rerum Novarum".

Insisti em que minha posse solene se realizasse hoje.

É o meu preito às idéias que difundiu, de uma ordem social mais justa, voltada para o homem e para a paz social.

Agradeço a presença dos Juízes do Tribunal Regional do Trabalho, meus incansáveis colegas de magistratura, que me prestigiam com suas presenças.

Tenho a certeza de que farei com os demais professores do meu Departamento um trabalho de equipe, único compatível com os fins da atividade universitária.

Muito obrigado, meu e dos meus familiares. 